\title{
The advantage of project risk management tools
}

\author{
Mohammad Reza Ghaelia*
}

${ }^{a}$ Adjunct Professor, School of Management, New York Institute of Technology, 1700 - 701 W Georgia St., Vancouver, BC V7Y 1 K8 Canada

\begin{tabular}{l}
\hline C H R O N I C L E \\
\hline Article history: \\
Received: July 5, 2017 \\
Received in revised format: Octo- \\
ber 10, 2017 \\
Accepted: December 5, 2017 \\
Available online: \\
January 2, 2018 \\
\hline Keywords: \\
Project risk management \\
Risk management process
\end{tabular}

\section{A B S T R A C T}

\begin{abstract}
Risk management plays an important role on the success of the any project. There are several techniques, which are available to help different phases of risk management process. This paper presents a survey to identify the necessary tools, which are mostly implemented and related to the success of any project management, and more specifically with effective project risk management. The survey is based on a questionnaire designed to a sample of project managers from the construction industries. The response data was studied to determine which tools are more used in the organizations, which could yield a better project management performance.
\end{abstract}

(C) 2018 by the authors; licensee Growing Science, Canada.

\section{Introduction}

The management of risk in high technology projects is presently considered as one of the primary issues among people who are working in the area of project management. Risk management is one of the eight primary areas of the Project Management Body of Knowledge (PMBOK) (Raz \& Michael, 2001; Larson \& Gray, 2013). Within the presently accepted perspective of project management as a life cycle process, project risk management (PRM) is also considered as a process that comes with the project from its definition through its planning, execution and control phases up to its completion and closure (Raz \& Michael, 2001; Patanakul et al., 2010). There are several versions of the PRM process and according to Boehm (1991), there are two phases with risk assessment, which includes "identification, analysis and prioritization, and risk control, which includes risk management planning, risk resolution and risk monitoring planning, tracking and corrective action”. Fairley (1994) specifies seven steps as "(1) Identify risk factors; (2) Assess risk probabilities and effects; (3) Develop strategies to mitigate identified risks; (4) Monitor risk factors; (5) Invoke a contingency plan; (6) Manage the crisis; (7) Recover from the crisis". Project risk management can be categorized in five distinct phases including identification; analysis; response planning; tracking and control associated with an ongoing risk communications efforts (Cervone, 2006). In other guidelines, there are four phases of the PRM process including identification; quantification; response development and control (Chapman \& Ward, 2003; 
McNeil et al., 2015). Kliem and Ludin (1997) explained a four-phase process including identification, analysis, controlling and reporting, which parallels Deming's four steps for quality management (Deming, 1981).

This paper presents a survey accomplished among a sample of project managers to find out the necessary tools, which are mostly used, the tools which help the success of the project management in general. In this context, the term "tool" is associated with a general meaning, including not only special purpose tools, but also practices and processes that are likely to help the management of risks in projects.

\section{The proposed study}

The sample size of the study includes all project managers who are involved in high tech industry in the world. Therefore, since the population is literally unlimited, according to Morgan table, we need to have 384 properly filled questionnaire, which were designed in Likert scale. The study sends the questionnaire first to some well-known experts. Cronbach alpha was calculated as 0.79 , which validates the questionnaire. Next, we used different social pages to distribute 450 questionnaires among the people who were involved in high tech project management and finally, we managed to collect 390 properly filled ones.

The questionnaire had three main sections, each containing a number of brief questions to be filled based on a 0-5 Likert scale. The first section was associated with the extent of the contribution of individual PRM tools to the project success in general. The objective here was to determine the tools perceived as being the most valuable by the respondents.

The questionnaire consists of a list of 38 tools and practices specified in the literature as contributing to PRM and it was adopted from the work earlier published by Raz and Michael (2001) and Table 1 shows the summary of the items as well as the scores given to each item. The tools were grouped according to the five stages of the Software Engineering Institute Risk Management process and Raz and Michael (2001) upgraded the tools by adding an additional group for tools, processes and practices of a general nature. The tools in this group is named as "Background", which is considered for the effects of the different issues in which risks are managed without being specifically associated with one of the five stages in the PRM cycle. The respondents were requested to rate the contribution of each tool to the PRM process by specifying a value between 0 (no contribution at all) to 5 (critical contribution). The results for the 38 tools are categorized into six groups and Table 1 demonstrates the mean and standard deviation of the responses.

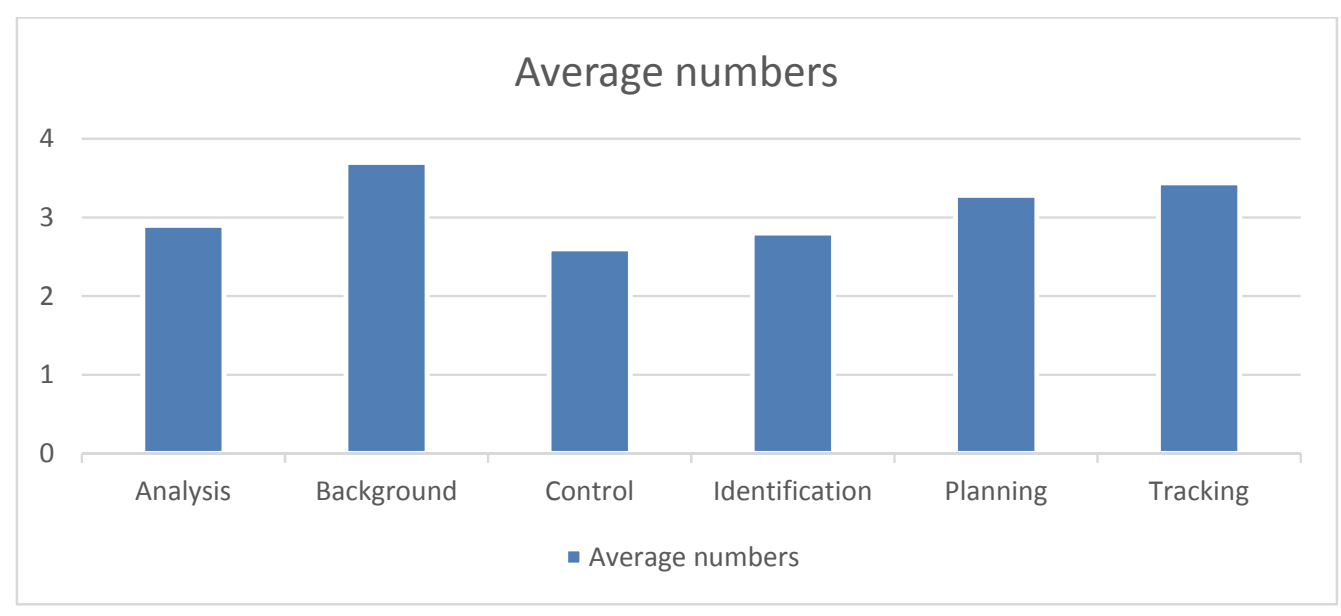

Fig. 1. The average numbers for each group 
Note that out of the ten tools that received the highest mean score, five of them are associated with the "Background" group, and that all the tools in this group maintained the scores above the overall average of 3.22 (See Fig. 1). This results indicate that risk management is tightly associated with other management practices, such as requirements management, subcontractor management, configuration control, and that the contribution of these kinds of organization-wide processes to effective project management was well recognized. The tools in the risk control group maintained as the low contributors.

\section{Table 1}

Descriptive statistics for the PRM tools

\begin{tabular}{|c|c|c|c|c|c|}
\hline Tool & Description & Group & Mean & Standard deviation & Ranking \\
\hline $\mathrm{T} 1$ & Checklists & Identification & 2.15 & 0.92 & 37 \\
\hline $\mathrm{T} 2$ & Brainstorming & Identification & 3.67 & 0.77 & 11 \\
\hline T3 & Risk documentation form & Identification & 2.55 & 0.92 & 31 \\
\hline $\mathrm{T} 4$ & Periodic risk reporting & Identification & 2.77 & 1.04 & 26 \\
\hline T5 & Risk probability assessment & Analysis & 3.45 & 1.09 & 15 \\
\hline T6 & Risk impact assessment & Analysis & 3.70 & 0.62 & 10 \\
\hline $\mathrm{T} 7$ & Risk time frame assessment & Analysis & 2.63 & 1.33 & 29 \\
\hline $\mathrm{T} 8$ & Risk classification & Analysis & 2.41 & 1.20 & 34 \\
\hline T9 & Ranking of risks & Analysis & 3.31 & 0.94 & 19 \\
\hline $\mathrm{T} 10$ & Graphic presentation of risk information & Analysis & 1.91 & 1.28 & 38 \\
\hline T11 & Responsibility assignment & Planning & 3.88 & 0.92 & 3 \\
\hline T12 & Planning for risk mitigation & Planning & 3.75 & 0.97 & 8 \\
\hline T13 & Time-limited action-item lists & Planning & 3.65 & 0.85 & 12 \\
\hline T14 & Cost-benefit assessment during risk planning & Planning & 2.75 & 1.12 & 27 \\
\hline T15 & Cause and effect analysis during risk planning & Planning & 2.45 & 1.08 & 32 \\
\hline T16 & Project re-planning for risk mitigation & Planning & 3.22 & 1.08 & 20 \\
\hline T17 & Revision of risk assessments & Tracking & 3.40 & 0.78 & 16 \\
\hline T18 & Periodic document reviews & Tracking & 3.22 & 1.04 & 21 \\
\hline T19 & Periodic risk status reporting & Tracking & 3.32 & 1.08 & 18 \\
\hline $\mathrm{T} 20$ & Periodic reporting of risk mitigation plans & Tracking & 2.87 & 0.95 & 24 \\
\hline $\mathrm{T} 21$ & Periodic trend reporting & Tracking & 2.61 & 1.04 & 30 \\
\hline $\mathrm{T} 22$ & Critical risk reporting to senior management & Tracking & 3.81 & 0.97 & 7 \\
\hline $\mathrm{T} 23$ & Analysis of trends, deviations and exceptions & Control & 2.71 & 0.95 & 28 \\
\hline $\mathrm{T} 24$ & Project re-planning & Control & 2.86 & 1.04 & 25 \\
\hline $\mathrm{T} 25$ & Procedure for closing risks & Control & 2.40 & 1.33 & 35 \\
\hline T26 & Contingency plans for risk mitigation failure & Control & 2.45 & 1.22 & 33 \\
\hline $\mathrm{T} 27$ & Cost-benefit analysis during risk control & Control & 2.88 & 1.12 & 23 \\
\hline $\mathrm{T} 28$ & Cause and effect analysis during risk control & Control & 2.33 & 0.98 & 36 \\
\hline T29 & Prototyping & Background & 3.85 & 1.04 & 5 \\
\hline $\mathrm{T} 30$ & Simulation & Background & 4.15 & 0.83 & 1 \\
\hline $\mathrm{T} 31$ & Benchmarking & Background & 3.63 & 0.85 & 13 \\
\hline T32 & Requirements management & Background & 3.73 & 0.86 & 9 \\
\hline T33 & Subcontractor management & Background & 3.84 & 0.95 & 6 \\
\hline T34 & Configuration control & Background & 3.93 & 0.72 & 2 \\
\hline $\mathrm{T} 35$ & Quality control & Background & 3.86 & 0.72 & 4 \\
\hline T36 & Quality management & Background & 3.45 & 0.72 & 14 \\
\hline T37 & Training programs & Background & 3.22 & 0.84 & 22 \\
\hline \multirow[t]{2}{*}{ T38 } & Customer satisfaction surveys & Background & 3.34 & 0.95 & 18 \\
\hline & Average across all tools & & 3.16 & 0.98 & \\
\hline
\end{tabular}

\section{Conclusion}

In this paper, we have presented an empirical investigation to identify the necessary tools, which were mostly implemented and related to the success of any project management, and more specifically with effective project risk management. The survey has determined six groups of factors; namely Analysis, Background, Control, Identification, Planning and Tracking. The results have indicated that many factors categorized as background maintained the most important effects on PRM tools followed by tracking, Planning and Analysis. The study could be extended to a more sophisticated analysis to investigate the relationship between PRM tools and financial figures in each firm and we leave it for interested researchers as a future study. 


\section{Acknowledgement}

The authors would like to thank the anonymous referees for constructive comments on earlier version of this paper.

\section{References}

Boehm, B. W. (1991). Software risk management: principles and practices. IEEE Software, 8(1), 3241.

Cervone, H. F. (2006). Project risk management. OCLC Systems \& Services: International Digital Library Perspectives, 22(4), 256-262.

Chapman, C., \& Ward, S. (2003). Project risk management: processes, techniques, and insights. Wiley. Deming, W. E. (1981). Improvement of quality and productivity through action by management. Global Business and Organizational Excellence, 1(1), 12-22.

Fairley, R. (1994). Risk management for software projects. IEEE Software, 11(3), 57-67.

Kliem, R. L., \& Ludin, I. S. (1997). Reducing project risk. Gower Publishing, Ltd.

Larson, E. W., \& Gray, C. (2013). Project Management: The Managerial Process with MS Project. McGraw-Hill.

McNeil, A. J., Frey, R., \& Embrechts, P. (2015). Quantitative risk management: Concepts, techniques and tools. Princeton university press.

Patanakul, P., Iewwongcharoen, B., \& Milosevic, D. (2010). An empirical study on the use of project management tools and techniques across project life-cycle and their impact on project success. Journal of General Management, 35(3), 41-66.

Raz, T., \& Michael, E. (2001). Use and benefits of tools for project risk management. International Journal of Project Management, 19(1), 9-17.

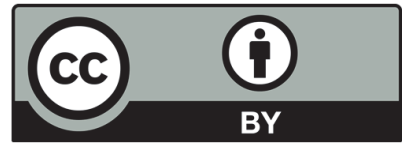

(C) 2018 by the authors; licensee Growing Science, Canada. This is an open access article distributed under the terms and conditions of the Creative Commons Attribution (CC-BY) license (http://creativecommons.org/licenses/by/4.0/). 